OPEN ACCESS

Edited by:

Antonis Kanellopoulos, University of Hertfordshire, United Kingdom

Reviewed by: George Wardeh, Université de Cergy-Pontoise, France Kevin Paine, University of Bath, United Kingdom

*Correspondence:

Ruben Paul Borg ruben.p.borg@um.edu.mt

Specialty section:

This article was submitted to Sustainable Design and Construction,

a section of the journal Frontiers in Built Environment

Received: 17 December 2018 Accepted: 29 April 2019

Published: 14 May 2019

Citation:

Farrugia $C$, Borg RP, Ferrara $L$ and Buhagiar J (2019) The Application of Lysinibacillus sphaericus for Surface Treatment and Crack Healing in Mortar. Front. Built Environ. 5:62. doi: 10.3389/fbuil.2019.00062

\section{The Application of Lysinibacillus sphaericus for Surface Treatment and Crack Healing in Mortar}

\author{
Christine Farrugia ${ }^{1}$, Ruben Paul Borg ${ }^{1 *}$, Liberato Ferrara ${ }^{2}$ and Joseph Buhagiar ${ }^{3,4}$ \\ ${ }^{1}$ Faculty for the Built Environment, University of Malta, Msida, Malta, ${ }^{2}$ Department of Civil and Environmental Engineering, \\ Politecnico di Milano, Milan, Italy, ${ }^{3}$ Department of Biology, University of Malta, Msida, Malta, ${ }^{4}$ Argotti Botanic Gardens and \\ Resource Centre, University of Malta, Msida, Malta
}

Micro-cracks, which develop during the service life of reinforced concrete structures, reduce the durability of concrete through the penetration of fluids. Microbially-induced calcium carbonate precipitation (MICP) occurs naturally in the presence of ureolytic bacteria which precipitate calcium carbonate $\left(\mathrm{CaCO}_{3}\right)$ through urea hydrolysis. This deposition leads to the filling of micro-cracks and sealing of pores, reducing ingress of fluids into the concrete. The research aims were to assess the potential of Lysinibacillus sphaericus for healing cracks in concrete and to study the effects of this treatment on the absorption properties of treated concrete. Lysinibacillus sphaericus was cultivated in vitro and induction of MICP through urea hydrolysis was tested on cement paste with two different calcium sources. The calcium precipitates where characterized by light microscopy, Scanning Electron Microscopy, Energy Dispersive Spectroscopy and Fourier Transform Infrared Spectroscopy. The final phase of the study involved testing of the crack healing capacity and the effect on absorption of the MICP process on mortar samples. These parameters were measured by means of visual examinations, light and digital microscopy, Ultrasonic Pulse Velocity (UPV), and absorption tests. The study confirmed that MICP is induced successfully on concrete using Lysinibacillus sphaericus. Samples exposed to repeated treatment cycles of Lysinibacillus sphaericus in the presence of a calcium source, exhibited a more extensive and even coating of $\mathrm{CaCO}_{3}$ crystals on the surface confirming that repeated cycles of treatment are more effective in increasing the amount of $\mathrm{CaCO}_{3}$ deposition and therefore increasing crack healing capacity. Digital microscopy and UPV analysis proved that this precipitate was successful in partially healing cracks in samples. Sorptivity tests confirmed this and showed that it was also successful as a surface treatment to reduce absorption.

\footnotetext{
Keywords: microbially-induced calcium carbonate precipitation, Lysinibacillus sphaericus, biocalcification, crack healing, surface treatment, concrete
}

\section{INTRODUCTION}

The development of new advanced cement-based materials leads to more durable concrete and reinforced concrete structures, with better performance throughout their intended life-time (Borg et al., 2018a). The durability of concrete is greatly reduced by the presence of micro-cracks within the material (Newman and Seng Choo, 2003). Micro-cracks may develop due to various processes 
and can occur at any time during the service life of the structure. They have a negative effect on the concrete as they allow ingress and transport of fluids into the concrete matrix, causing corrosion of reinforcement and degradation of the cementitious matrix. Therefore, crack widths must be controlled and healing processes may be promoted to reduce the ingress of fluids. Micro-cracks in concrete can heal naturally through autogenous healing which also involves the precipitation of calcium carbonate $\left(\mathrm{CaCO}_{3}\right)$ inside the crack in the presence of water. However, autogenous healing is only possible in small cracks and takes a long time to occur (De Belie et al., 2018).

Various researchers have investigated the self-healing mechanisms in cement based materials, including the experimental methods and techniques which have been employed to characterize and quantify the self-sealing and/or self-healing capacity of cement-based materials, the effectiveness of the different self-sealing and/or self-healing engineering techniques, and also the methods for the analysis of the chemical composition and intrinsic nature of the self-healing products (Liberato et al., 2018). Cement based materials incorporating supplementary cementitious materials and also self-healing enhancing crystalline admixtures have been developed and their effectiveness and capacity for crack sealing has been investigated in different environments such as chloride-rich environments (Ferrara et al., 2014, 2016; Borg et al., 2018b; Cuenca et al., 2018; Escoffres et al., 2018).

Cracks may also heal through a microbial process known as microbial-induced calcium carbonate precipitation (MICP). This biological repair by bio-deposition mimics what occurs naturally with ureolytic bacteria that can precipitate $\mathrm{CaCO}_{3}$ in the presence of appropriate nutrients (De Belie et al., 2010a; Farrugia et al., 2018). The process can be induced artificially in the laboratory by adding urea to the medium containing the appropriate bacteria. The $\mathrm{CaCO}_{3}$ precipitation allows rapid filling of cracks in concrete and plugging of pores to reduce absorption of fluids. As opposed to autogenous healing, this process can therefore seal cracks a lot quicker and avoid further damage occurring.

Bio-deposition methods as opposed to conventional surface treatments and crack repair methods with synthetic chemicals and formulations are alternative and eco-friendly techniques which merit further investigation. MICP is a natural, nonpolluting process which has no damaging effects on the natural environment and therefore can be promoted as a viable alternative to conventional, often environmentallypolluting treatments on concrete. The aims of this research were to assess the potential for healing of cracks in cement based mortar through the use of Lysinibacillus sphaericus in the presence of different calcium sources and to study the effects of this treatment on the absorption properties of the mortar.

The innovation presented in the study refers mainly to the effective use of Lysinibacillus sphaericus as the bacteria in the presence of different calcium sources and effective microbiallyinduced calcium carbonate precipitation (MICP) for surface sealing and crack healing.

\section{MATERIALS AND METHODS}

\section{Research Methodology}

The first phase of the research refers to the preparation of the microbiological material used throughout the research. This phase included the preparation of the agar system, the Medium 295 broth system supplemented with urea and the preparation of the Lysinibacillus sphaericus (LMG 22257) bacterial inoculum whose growth curve was determined. Calcium source solutions namely calcium chloride $(\mathrm{CaCl} 2)$ and calcium acetate $(\mathrm{Ca}(\mathrm{CH} 3 \mathrm{COO}) 2)$ were also prepared in this phase.

In the second phase of the research a study was first carried out to ascertain that the bacterial inoculum and the calcium source prepared were able to induce microbial calcium carbonate precipitation (MICP) on cement paste samples. Once the presence of a precipitate on the surface of the cement paste samples was confirmed, a similar methodology was used to prepare and treat cement paste samples which would allow the precipitate on the surface to be characterized.

In third phase of the research, cracked and uncracked mortar samples were used to test the crack healing capacity and the effect on the absorption characteristics of the samples respectively using this treatment procedure. An overview of the research methodology used is presented in Table 1.

\section{Preparation of Medium and Bacterial Inoculum for Bio-precipitation}

Lysinibacillus sphaericus (LMG 22257) used in this study, was obtained as a lyophilised ampoule from the Belgian Co-ordinated Collections of Micro-organisms (BCCM). This strain of bacteria is alkaliphilic and was reported to have a continuous formation of dense calcium carbonate crystals in previous studies (Chahal and Siddique, 2011). Medium 295 agar was prepared using recommended protocol provided by BCCM. Medium 295 broth was similarly prepared but the addition of agar was omitted. The autoclaved agar medium was poured into sterile petri dishes and the sterile broth was later used for bacterial revival and surface inoculation. The bacteria were revived by using $0.5 \mathrm{ml}$ of Medium 295 broth, allowing enough time to rehydrate before transferring onto a Medium 295 agar plate and streaked to obtain individual colonies after incubation for 48$72 \mathrm{~h}$ at $30^{\circ} \mathrm{C}$. The remaining drops of hydrated L. sphaericus were added to Medium 295 broth to prepare a liquid culture and similarly incubated. The bacterial colonies were repeatedly sub-cultured over a period of time to increase the volume of bacterial inoculum required for bio-precipitation. In order to induce sporulation, the same procedure of bacterial subculture was used but the agar medium was further modified by the addition of $10 \mathrm{mg} / \mathrm{L}$ of $\mathrm{MnSO}_{4}$ to the Medium 295 agar. For the preparation of the bacterial inoculum for the bioprecipitation experiments, a $0.5 \mathrm{McF}$ arland bacterial inoculum in Medium 295 broth was prepared by comparison to barium sulfate standard prepared using standard protocol. The solution was incubated for $24 \mathrm{~h}$ at $30^{\circ} \mathrm{C}$ to obtain a 1-day old stock culture. This procedure was repeated using a plate containing 


\begin{tabular}{|c|c|c|c|}
\hline Phase & Set reference & Objective & Experiment \\
\hline 1 & Preliminary investigation & $\begin{array}{l}\text { To ascertain that microbial calcium carbonate precipitation could be } \\
\text { induced. }\end{array}$ & Visual Observation, Stereomicroscopy \\
\hline 2 & Cement Paste Samples & $\begin{array}{l}\text { To characterize the precipitates from microbial-induced calcium } \\
\text { carbonate precipitation. }\end{array}$ & $\begin{array}{l}\text { Visual Observation, Stereomicroscopy, FTIR, } \\
\text { SEM, EDS }\end{array}$ \\
\hline 3 & Mortar Samples & $\begin{array}{l}\text { To test the crack healing capacity and effect on absorption of } \\
\text { microbial-induced calcium carbonate precipitation. }\end{array}$ & $\begin{array}{l}\text { Visual Observation, Digital Microscopy, UPV, } \\
\text { Sorptivity }\end{array}$ \\
\hline
\end{tabular}

L. sphaericus (LMG 22257) and Medium 295 agar with $10 \mathrm{mg}$ of $\mathrm{MnSO}_{4}$.

\section{Preparation of Calcium Source Solutions}

A solution of calcium chloride $\left(\mathrm{CaCl}_{2}\right)$ was prepared by adding $6.25 \mathrm{~g}$ of $\mathrm{CaCl}_{2}$ to $250 \mathrm{~mL}$ of distilled water. A solution of calcium acetate $\left(\mathrm{Ca}\left(\mathrm{CH}_{3} \mathrm{COO}\right)_{2}\right)$ was prepared by adding $6.5 \mathrm{~g}$ of $\mathrm{Ca}\left(\mathrm{CH}_{3} \mathrm{COO}\right)_{2}$ to $250 \mathrm{~mL}$ of distilled water. Both solutions were subsequently autoclaved and set aside.

\section{Preparation of Cement Paste Samples}

Five hundred grams of CEM $142,5 \mathrm{R}$ cement and $140 \mathrm{ml}$ of distilled water were mixed for $2.5 \mathrm{~min}$ at 285 r.p.m. in a 5 liter bowl. The cap of a $1 \mathrm{~mL}$ Eppendorf flask was isolated from the flask so as to obtain a mold which could hold circa $0.15-0.2 \mathrm{~g}$ of cement paste. The cement paste was placed in the molds and vibrated on a vibrating table. They were then allowed to cure inside an enclosed container at $20 \pm 1^{\circ} \mathrm{C}$ and a relative humidity of $70 \%$.

\section{Treatment Procedure for Cement Paste Samples}

The upper surface of the pre-labeled cement paste samples were sterilized under UV for $40 \mathrm{~min}$ and placed inside sterilized containers so as to avoid contamination. The bacterial inoculum broth was applied to the surface of the samples using a sterile micropipette until ponding was achieved on top of the sample. The samples were left to stand in an enclosed container for $24 \mathrm{~h}$ at room temperature after which any remaining bacterial inoculum on the surface of the samples was gently pipetted so that ureolytic activity would result primarily from bacteria immediately on the cement paste. Calcium chloride or calcium acetate solution was similarly applied in excess to the surface of the samples. These were left to stand in an enclosed container for $72 \mathrm{~h}$ also at room temperature, after which any remaining calcium solution was removed. For one set of samples a second application of bacterial inoculum was repeated at the end of the first treatment. All treatment procedures were carried out in duplicate with adequate controls in place. The samples were observed at 1,3, and 8 day intervals post treatment, first visually, then using stereoscopic microscopy, Fourier Transform Infrared Spectroscopy (FTIR), Scanning Electron Microscopy (SEM), and Energy Dispersive Spectroscopy (EDS). Digital photographic records and measurements were made in all instances.

\section{Preparation of Mortar Samples}

Mortar samples were produced and tested in the cracked and uncracked state to assess the healing of cracks and also the surface sealing potential. For the production of mortar, 2,700 g of CEM $142,5 \mathrm{R}$ cement and $1,890 \mathrm{ml}$ of distilled water were mixed for $2.5 \mathrm{~min}$ at 285 r.p.m. $8,100 \mathrm{~g}$ of local sand (apparent particle density of $2,696 \mathrm{~kg} / \mathrm{m} 3$ and $\mathrm{WA}_{24}$, of $4.9 \%$ ) and $405 \mathrm{ml}$ of distilled water to make up for the sand's absorption were added to the mix and mixed for a further $2 \mathrm{~min}$. The mortar was cast into prismatic molds to produce specimen with a crosssectional area of $40 \times 40 \mathrm{~mm}$ and $160 \mathrm{~mm}$ long. The prisms were vibrated on a vibrating table until good compaction was achieved. The specimens were cured for $24 \mathrm{~h}$ at $20 \pm 1^{\circ} \mathrm{C}$ and a relative humidity of $70 \%$. They were then de-molded and placed inside a plastic container containing distilled water at $20 \pm 1^{\circ} \mathrm{C}$. For the purpose of the research additional samples were produced, consisting of $40 \mathrm{~mm}$ cubic specimen, which were trimmed from the ends of the prisms.

\section{Cracking of Mortar Samples}

A method of "simulated cracking" as outlined by Dudi et al. was used to crack the mortar specimens after 28 days of curing (Dudi et al., 2010). This method involved the production of "simulated cracks" which were obtained by splitting the prismatic sample through the middle into two halves and then fixing the halves back together at their edge with Araldite Resin whilst leaving the required crack width in between. A digital microscope was used to measure the crack width of between 0.2 and $0.3 \mathrm{~mm}$. Dudi et al. argued that this method simulated the "worst case scenario" as the 2 halves of the sample where completely separated and there was a full loss of structural strength between the two halves (Dudi et al., 2010). They also argued that this method allowed complete control over the crack width obtained unlike other methods.

For the purposes of this experiment, $160 \times 40 \times 40 \mathrm{~mm}$ prisms were placed into a 3-point flexural bending machine and loaded until failure. The load at which they failed was recorded. The two halves of the prisms were brought together under a digital microscope and held in place using Araldite resin on 2 opposite outer faces of the prism. The crack width was measured on the 2 faces of the prism which did not have any resin. For each face, 9 measurements of the crack width were taken using a digital microscope at a magnification of 205x; 3 measurements were taken toward the top of the crack, 3 measurements toward the middle and 3 measurements toward the bottom of the crack. The average crack widths were found for these three points and along the entire crack. 


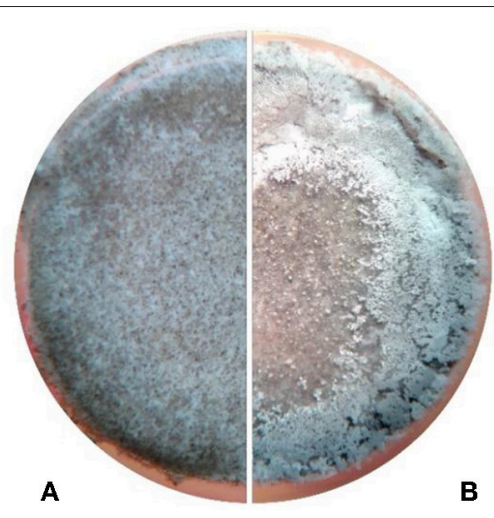

FIGURE 1 | Stereoscopic microscopy images of the surface of cement paste specimens. (A) Control -treated with $\mathrm{CaCl}_{2}$. but not bacterium (B) treated with L. sphaericus and $\mathrm{CaCl}_{2}$.

The cubic specimen were cracked through the application of a knife-edge load on the specimen and then a similar procedure as that used for the prisms was adopted for the resulting two parts of the cubic specimen.

\section{Treatment Procedure for Mortar Samples}

Cracked and uncracked mortar prism samples were placed in a plastic box filled with 1 liter of Medium 295 broth containing the bacterial inoculum. The bottom half of each prism was immersed in the bacterial inoculum and each prism was rotated on a different face every few hours to ensure even exposure time. The prisms were left to stand in the enclosed container for a total of $24 \mathrm{~h}$, after which they were transferred to boxes containing 1 liter of $\mathrm{Ca}\left(\mathrm{CH}_{3} \mathrm{COO}\right)_{2}$ or $\mathrm{CaCl}_{2}$ calcium source depending on their respective treatment procedures. The samples were then left to stand in the enclosed containers for $72 \mathrm{~h}$.

The same treatment procedure was also applied to the cubic specimen. In this case, the cracked and un-cracked cubes were fully immersed in the bacterial inoculum for the whole $24 \mathrm{~h}$ inoculation period due to their smaller size. The variables in the treatment procedure were the presence or absence of L. sphaericus and the presence and type of calcium source. All treatment procedures were carried out in duplicate with adequate controls.

After treatment, all samples were placed in a clean plastic container and left to dry at $20 \pm 1^{\circ} \mathrm{C}$ and a relative humidity of $70 \%$ for 7 days before any tests were carried out. The samples were observed by visual observation, digital microscopy, Ultrasonic Pulse Velocity (UPV) and a Sorptivity Test. Digital photographic records and measurements were made in all instances.

\section{Mortar Testing}

All samples were photographed and the type of deposition obtained was observed and recorded. A digital microscope was used to observe the surface deposition and the cracked samples in order to characterize the crack healing capacity and also the amount and type of deposition present. Ultrasonic Pulse Velocity

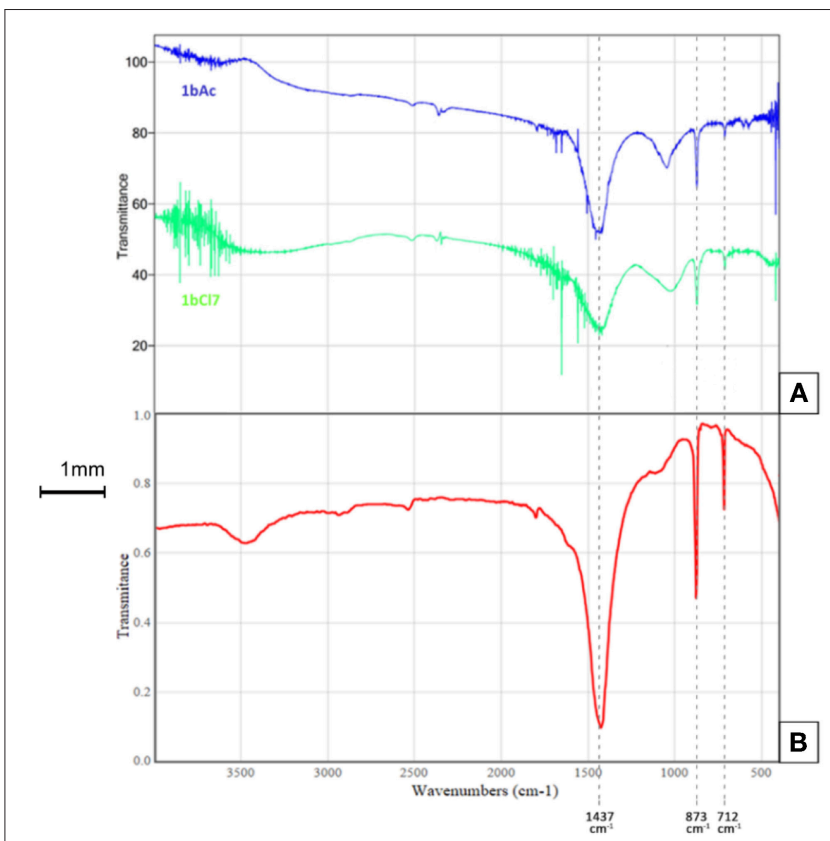

FIGURE 2 | FTIR spectra for (A) scraping from surface of sample $1 \mathrm{bCl} 7$ treated with $L$. sphaericus and $\mathrm{CaCl}_{2}$ (green) and $1 \mathrm{bAc} 7$ treated with $L$. sphaericus and $\mathrm{Ca}\left(\mathrm{CH}_{3} \mathrm{COO}\right)_{2}$ (blue), (B) reference spectrum for calcite (Calcium carbonate, 2016).

tests was carried out on all cracked and un-cracked samples to EN12504-4:2004, with the objective of assessing the degree of healing. The sorptivity test was conducted to assess the rate of water absorption of the samples and therefore the increase in resistance to water penetration through surface sealing. The samples were placed in an oven at $50^{\circ} \mathrm{C}$ and dried until a constant mass was reached. The sides of the samples were coated using an epoxy resin and this was allowed to harden for $25 \mathrm{~h}$. Subsequently the samples were placed in a plastic container elevated on plastic rods. Water was poured into the container until the water level reached $2-3 \mathrm{~mm}$ above the base of the sample. The test was carried out in a laboratory environment at $20 \pm 1^{\circ} \mathrm{C}$ and a relative humidity of $70 \%$. The samples were removed from the container and weighed at pre-established time intervals. The samples were dried gently using a paper towel before weighing.

\section{RESULTS AND DISCUSSION}

\section{Stereomicroscopy}

The cement paste samples were observed under a stereomicroscope to confirm the presence of calcium carbonate crystal deposition on the surface. In Figure 1, the surface of a control sample with no microbial treatment and a sample treated with $L$. sphaericus and $\mathrm{CaCl}_{2}$ under a stereomicroscope can be seen. The control sample on the left exhibits no precipitates while the treated sample on the right exhibits white precipitates on its surface. 


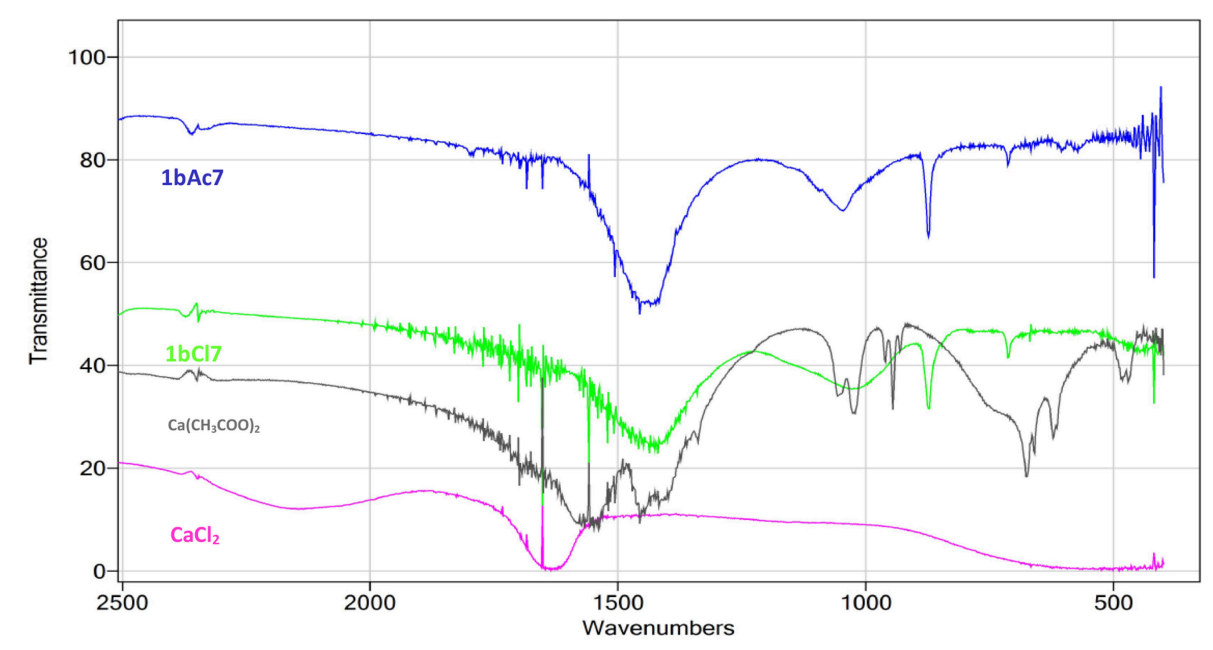

FIGURE 3 | FTIR spectra for scraping from surface of samples $1 \mathrm{bAc} 7$ (treated with $\mathrm{L}$. sphaericus and $\left.\mathrm{Ca}(\mathrm{CH} 3 \mathrm{COO})_{2}\right), 1 \mathrm{bCl}$ (treated with $\mathrm{L}$. sphaericus and $\mathrm{CaCl}$ ), and spectra for samples of $\mathrm{Ca}(\mathrm{CH} 3 \mathrm{COO})_{2}$ and $\mathrm{CaCl}_{2}$.

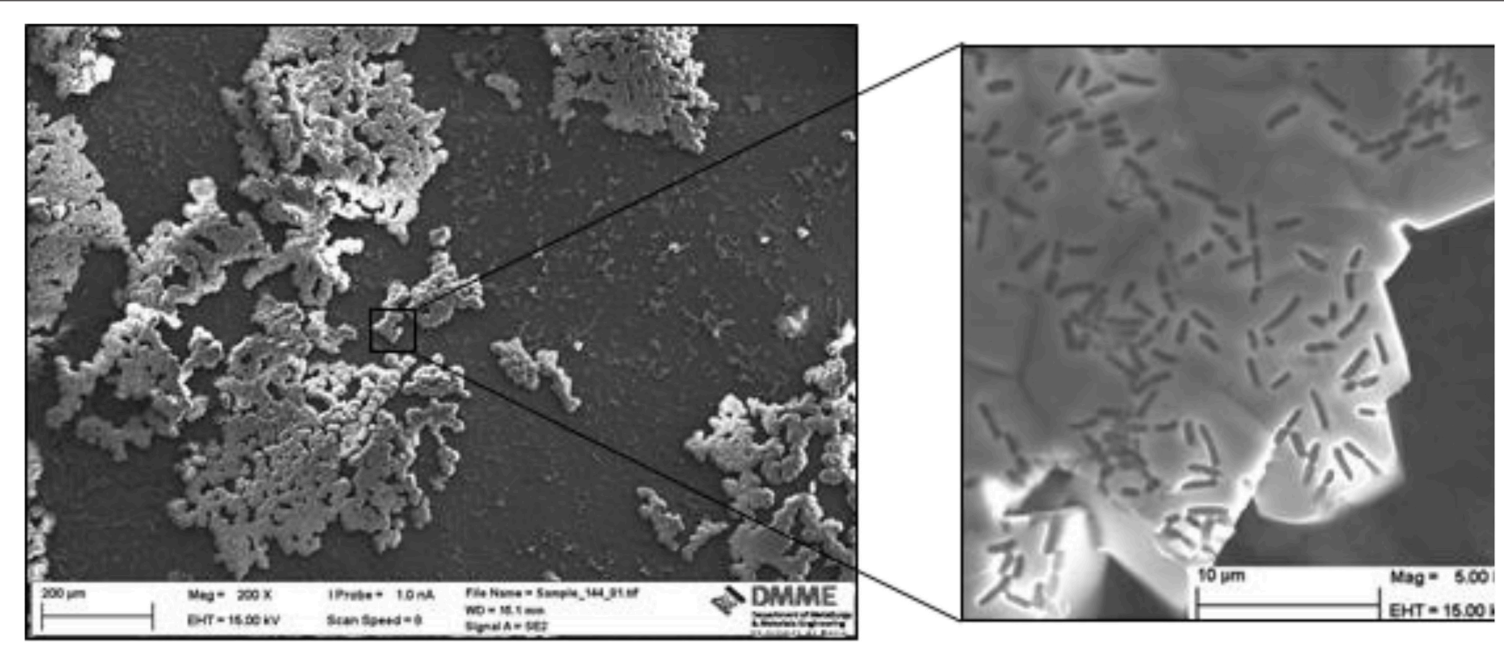

FIGURE 4 | SEM image for sample 1bAc7 treated with L. sphaericus and calcium acetate at 200X (left) and 5,000X magnification (right). The outline of the microbes embedded in the calcite biodeposition is clearly visible in the enlarged section.

\section{Fourier Transform Infrared Spectroscopy}

The Fourier Transform Infrared Spectroscopy (FTIR) spectra in the range of $500-4,000 \mathrm{~cm}^{-1}$ for the scraping of crystals from the surface of sample $1 \mathrm{bCl} 7$ (treated with L. sphaericus and $\mathrm{CaCl}_{2}$ ) and $1 \mathrm{bAc} 7$ (treated with L. sphaericus and $\left(\mathrm{Ca}\left(\mathrm{CH}_{3} \mathrm{COO}\right)_{2}\right)$ can be seen in Figure 2. The major peaks of the spectra in the treated samples correspond to the peaks of calcite which indicates the presence of $\mathrm{CaCO}_{3}$ deposition. The FTIR spectrum for calcite (Figure 2B), gives major vibrational bands peaks at 1,437, 873, and 712. This confirms that the precipitate obtained on the surface of the cement paste samples is calcite $\left(\mathrm{CaCO}_{3}\right)$. FTIR was also performed on samples of the $\mathrm{Ca}\left(\mathrm{CH}_{3} \mathrm{COO}\right)_{2}$ and $\mathrm{CaCl}_{2}$ used during treatment to ensure that the crystals on the surface of samples treated with bacteria and a calcium source were not precipitates of these compounds. This was confirmed as the
FTIR spectra obtained for these two compounds did not match that obtained for the surface crystals. The spectra in the range of 2,500-500 $\mathrm{cm}^{-1}$ showing calcite (1bAc7, 1bCl7) and those showing $\mathrm{Ca}\left(\mathrm{CH}_{3} \mathrm{COO}\right)_{2}$ and $\mathrm{CaCl}_{2}$ can be seen in Figure 3 .

\section{Scanning Electron Microscopy and Energy Dispersive Spectroscopy}

It was observed that Sample 1bAc7 treated with L. sphaericus and calcium acetate exhibited encrustations of crystals on its surface (Figure 4). Using SEM at a magnification of 5,000X, the crystals were clearly observed to be rhombohedral with sharp edges and with a size ranging from 10 to $15 \mu \mathrm{m}$. Within these rhombohedral crystals, rod-shaped lacunae corresponding to bacterial cell outline were observed. The shape and size also corresponds to the $2 \mu \mathrm{m}$ average length typical of these bacteria. 


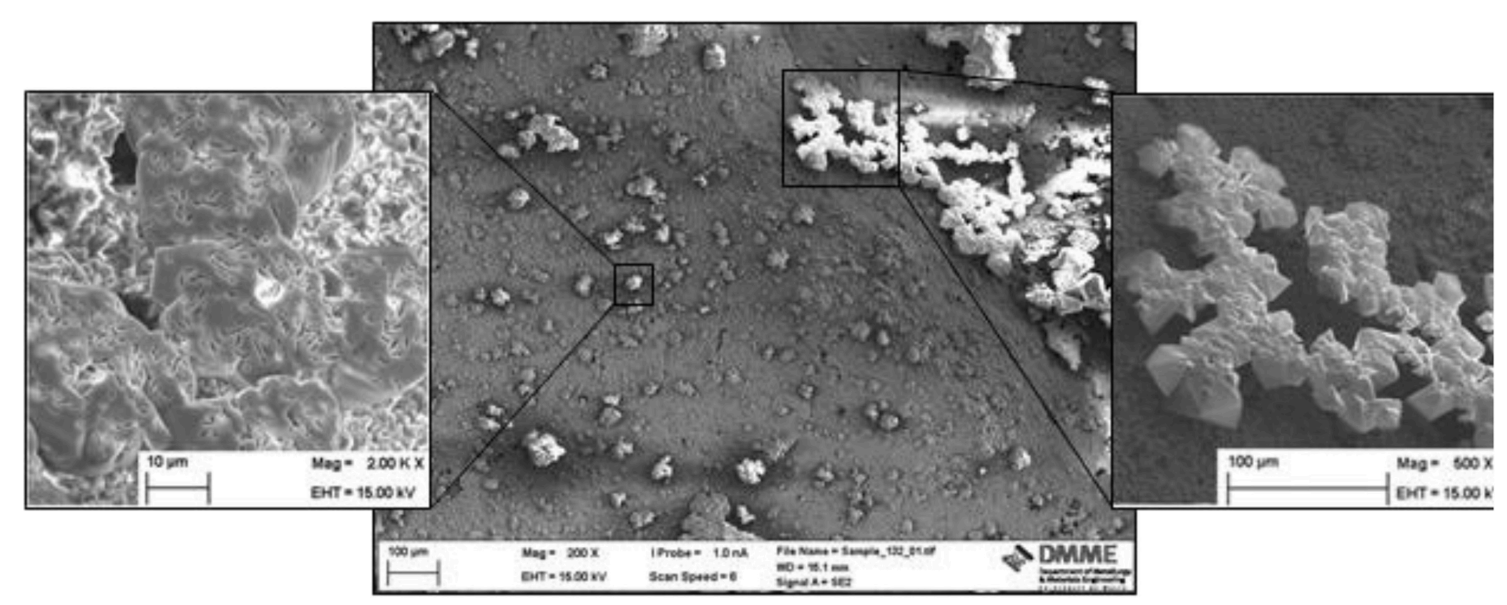

FIGURE 5 | SEM image for sample 2/1bCl7 which received two rounds of $L$. sphaericus and $\mathrm{CaCl}_{2}$. Image magnification: Centre 200X, left enlargement 2,000X right enlargement 500X. Note the bacterial lacunae in the enlarged image on the left.

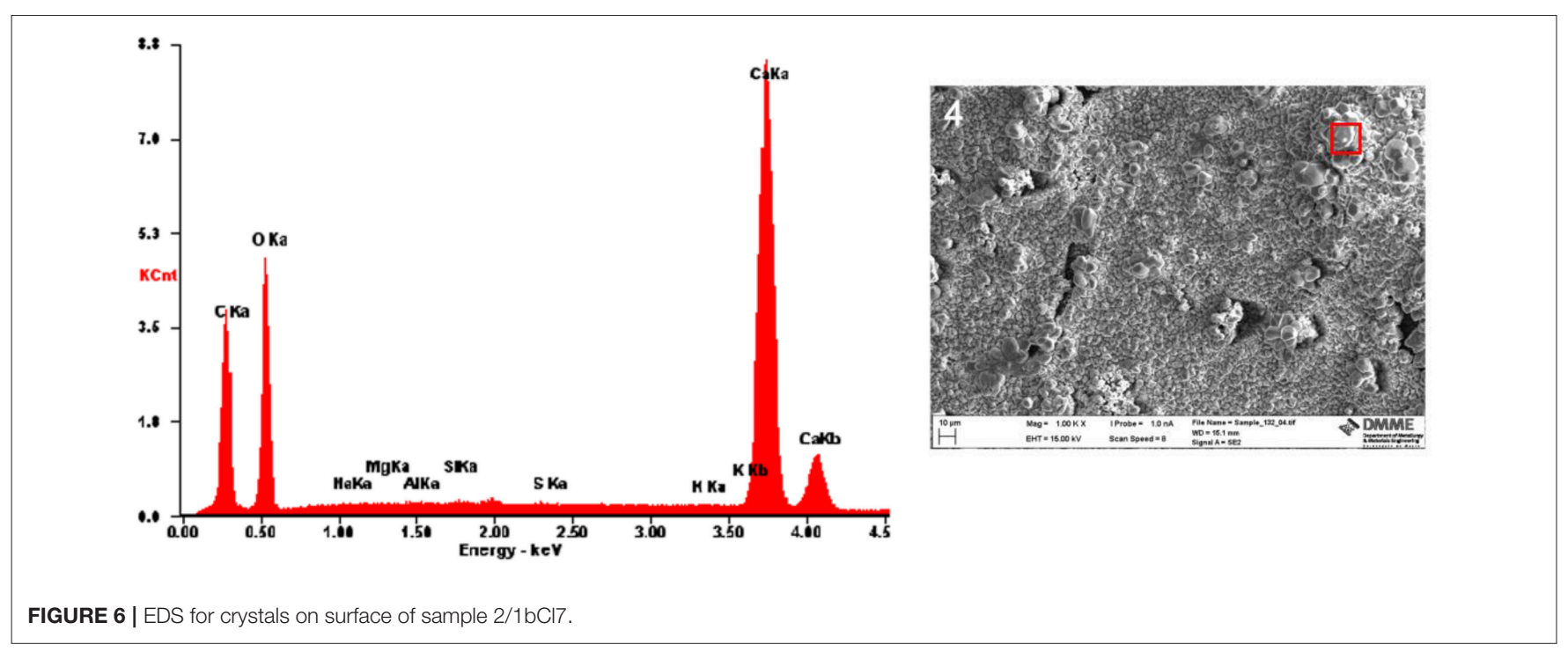

This confirms that the crystals are a product of the bio-deposition process induced using L. sphaericus and a calcium source. Sample $2 / 1 \mathrm{bCl} 7$ treated with two rounds of L. sphaericus and $\mathrm{CaCl}_{2}$ also exhibited crystal encrustation on its surface similar to those precipitated on sample $1 \mathrm{bAc} 7$. These crystals were also observed to be rhombohedral with sharp edges typical of calcite and bacterial cells could be observed within the crystals (Figure 5).

As opposed to the crystals precipitated on sample 1bAc7, the crystals precipitated on sample $2 / 1 \mathrm{bCl}$ covered the whole surface of the cement paste. This was confirmed through SEM energy dispersive spectroscopy (EDS) analysis of the surface of the sample (Figure 6) where no peaks for $\mathrm{Mg}, \mathrm{Si}, \mathrm{Al}$ and $S$ were shown indicating that the surface of the cement paste was entirely covered in crystals produced through MICP. Also, various different sizes of crystals were observed on the surface. On average, the size of the crystals ranged from 2 to $50 \mu \mathrm{m}$.

These differences between sample 1bAc7 and sample 2/1bCl7 were attributed to the fact that the latter received 2 rounds of treatment of L. sphaericus and the calcium source. This resulted in a more even coating on the surface and larger crystal depositions. Furthermore, the microbial lacunae were again clearly visible, confirming MICP.

\section{Digital Microscopy of Cracked Mortar Cubes}

The precipitate deposited along the cracks on the cracked mortar cubes were studied under a digital microscope at a magnification of 205x. Whilst the control sample exhibited no white precipitate along the crack, the four samples treated with L. sphaericus and a calcium source exhibited different degrees of crack healing along the crack. In some cases, the crack was fully healed (Figure 7) and in others, crystals precipitated along the edge of the crack but did not bridge the full width of the crack. This may be related to the $\mathrm{pH}$ of the mortar which could contribute to the performance of the bacteria. De Belie et al., have shown that cracked samples with a crack width of $\sim 0.2 \mathrm{~mm}$ treated with $L$. sphaericus and 

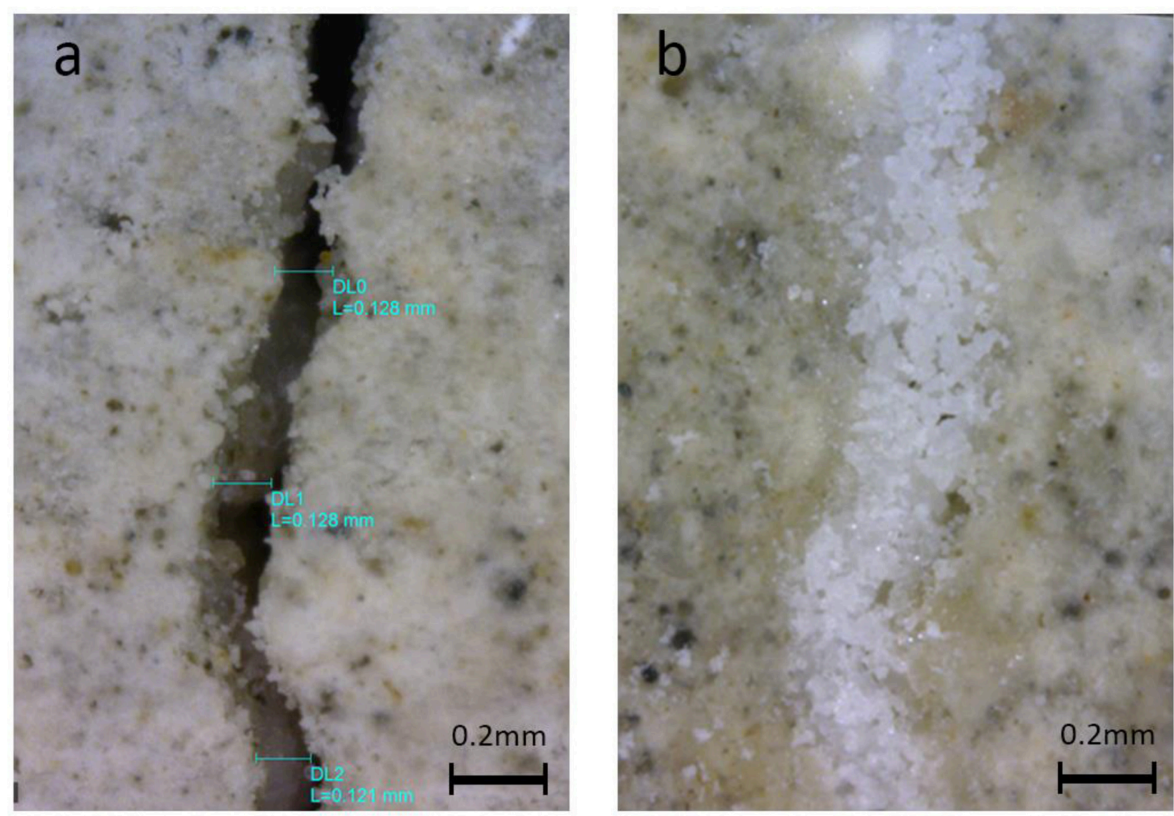

FIGURE 7 | Digital microscopy images of (a) untreated crack before treatment and (b) crack treated with L. sphaericus and $\mathrm{Ca}\left(\mathrm{CH}_{3} \mathrm{COO}\right)_{2}$.

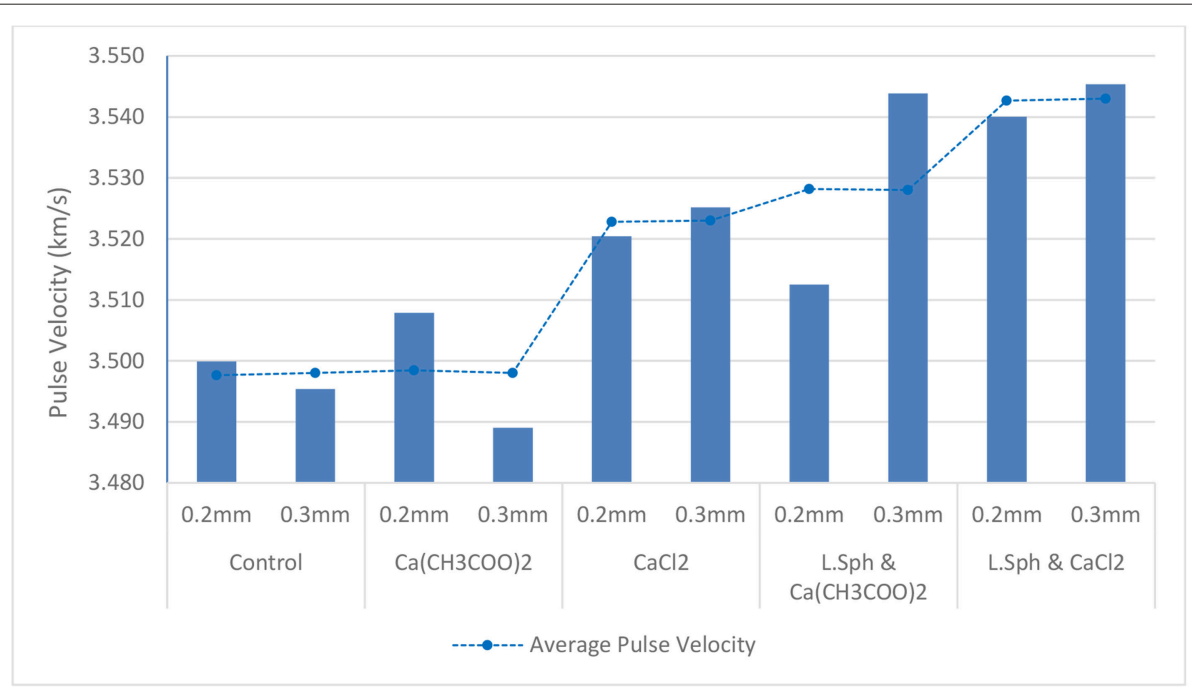

FIGURE 8 | Graph showing pulse velocity for cracked samples with 0.2 and $0.3 \mathrm{~mm}$ cracks after Calcium source treatment with and without bacteria, compared to un-cracked un-treated control. The average pulse velocity for 0.2 and $03 \mathrm{~mm}$ cracks is indicated as a dotted trendline.

a calcium source exhibited almost no $\mathrm{CaCO}_{3}$ crystal deposition along the crack, whereas when the L. sphaericus was immobilized in sol-gel, the crack healed completely (De Belie et al., 2010b). They attributed this phenomenon to the high $\mathrm{pH}$ of concrete and argued that when bacteria were immobilized in sol-gel, it was protected against the high $\mathrm{pH}$ and could remain active for longer.

The maximum size of the part of the crack which showed full healing was $0.2 \mathrm{~mm}$ wide and no significant difference was observed between the samples treated with $L$. sphaericus and $\mathrm{CaCl}_{2}$ and L. sphaericus and $\mathrm{Ca}\left(\mathrm{CH}_{3} \mathrm{COO}\right)_{2}$. All crack healing observed was attributed to deposition from the MICP process. Carbonation of the sample was neglected as the specimens were fully immersed in water until treated and therefore, did not come into contact with carbon dioxide from the atmosphere.

\section{Ultrasonic Pulse Velocity}

The ultrasonic pulse velocity (UPV) test was used to study the propagation of an ultrasonic wave through samples which had undergone different treatment procedures. Cracks and voids in a sample will increase the transmission time of the wave. Therefore, 


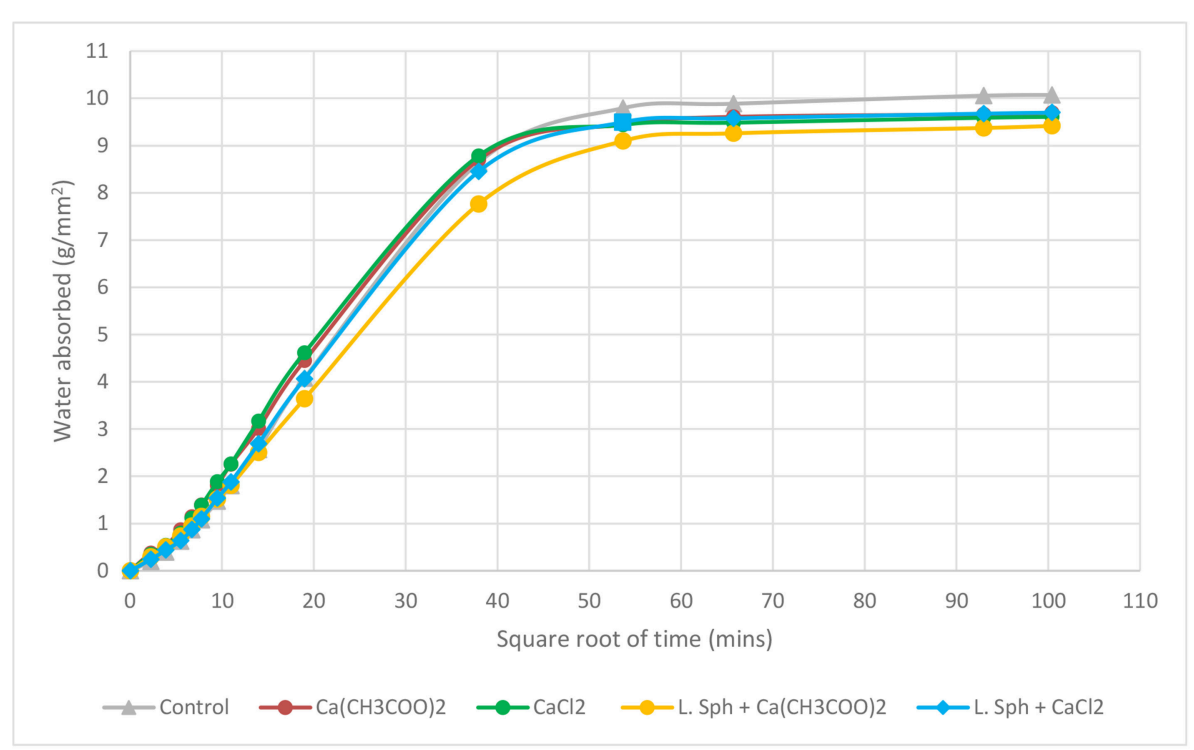

FIGURE 9 | Average water absorption vs. immersion time for uncracked mortar prisms.

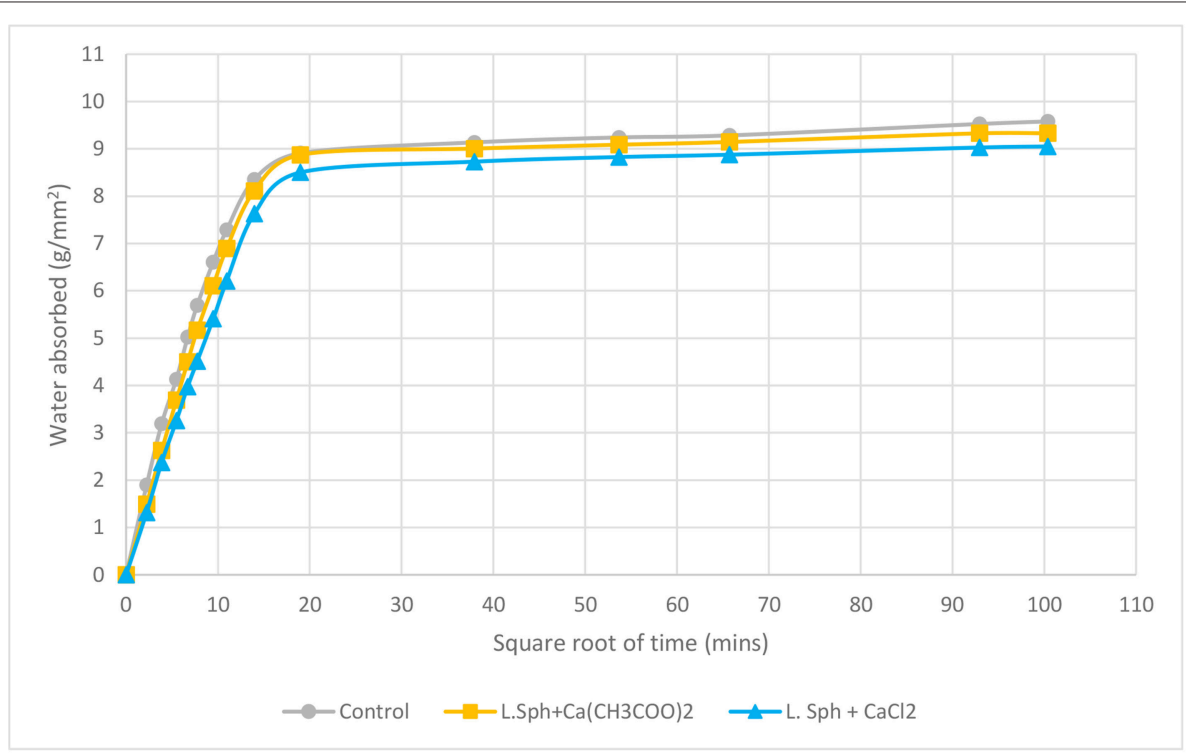

FIGURE 10 | Average water absorption vs. immersion time for cracked mortar cubes.

if the crack and voids are partially filled with precipitates from the treatment procedure, the wave will travel through the sample more rapidly. All cracked prisms were tested. Four readings for each prism were taken with the sample rotated on a different face each time. The values for pulse velocity are shown in Figure 8.

The highest average pulse velocity was obtained for the samples exposed to the treatment procedure consisting of $L$. sphaericus and $\mathrm{CaCl}_{2}$. A very similar value was obtained for the sample having a crack width of $0.3 \mathrm{~mm}$ and exposed to $L$. sphaericus and $\mathrm{Ca}\left(\mathrm{CH}_{3} \mathrm{COO}\right)_{2}$. However, the sample having a crack width of $0.2 \mathrm{~mm}$ exposed to the same treatment, exhibited a lower value. This may be due to the fact that the precipitate did not penetrate as deeply into this crack. When compared to the average pulse velocity for the control sample (3.498 $\mathrm{km} / \mathrm{s}$ ), the samples treated with L. sphaericus and $\mathrm{CaCl}_{2}$ and those treated with $L$. sphaericus and $\mathrm{Ca}\left(\mathrm{CH}_{3} \mathrm{COO}\right)_{2}$ exhibited an increase in pulse velocity of 0.045 and $0.03 \mathrm{~km} / \mathrm{s}$, respectively. This corresponds to a decrease in transmission time of 0.8 and $0.45 \mu \mathrm{s}$, respectively. This proves that the treatment procedure reduced the number of voids and/or reduced the crack width which resulted in a decrease in transmission time. The samples treated with $\mathrm{Ca}\left(\mathrm{CH}_{3} \mathrm{COO}\right)_{2}$ only did not exhibit a difference in 
average pulse velocity from the control sample. However, those treated with $\mathrm{CaCl}_{2}$ only exhibited an increase of $0.025 \mathrm{~km} / \mathrm{s}(0.5$ $\mu \mathrm{s})$. This is attributed to the precipitation of $\mathrm{CaCl}_{2}$ crystals in the voids within the sample. The decrease in ultrasonic wave transmission time for treated samples was confirmed by De Belie et al. (2010b). They showed that for samples treated with $L$. sphaericus and $\mathrm{CaCl}_{2}$, a decrease in transmission time of 0.6 $\mu \mathrm{s}$ was obtained for samples having a crack width of $0.3 \mathrm{~mm}$ at a depth of $10 \mathrm{~mm}$. Similarly, samples having a crack width of $0.3 \mathrm{~mm}$ at a depth of $20 \mathrm{~mm}$ exposed to the same treatment exhibited a decrease in transmission time of $1.2 \mu \mathrm{s}$.

\section{Sorptivity}

The effects of the treatment procedure on the rate of water absorption of the samples was studied. A sorptivity test carried out on uncracked prisms showed that the samples treated with bacteria and a calcium source exhibited slightly less water absorption when compared to the untreated prisms as illustrated in Figure 9. This decrease in water absorption can be attributed to the precipitation of crystals in the voids and on the surface of the treated sample which hinders the movement of water. This shows that the biodeposition treatment may be used as a coating system to slow down and partially hinder the entrance of liquids into the sample. The samples treated with a calcium source only also showed a decrease in the amount of water absorbed. This was attributed to the precipitation of a layer of $\mathrm{Ca}\left(\mathrm{CH}_{3} \mathrm{COO}\right)_{2}$ or $\mathrm{CaCl}_{2}$ on the surface.

A sorptivity test was also carried out on cracked mortar cubes. As expected, the samples treated with bacteria and a calcium source exhibited less water absorption than the control cracked sample indicating that the crack had partially healed and some voids had been blocked thanks to the biodeposition treatment (Figure 10). The sample treated with L. sphaericus and $\mathrm{CaCl}_{2}$ exhibited slightly less water absorption on average. This was additionally confirmed from visual observation, where one of the samples treated with $L$. sphaericus and $\mathrm{CaCl}_{2}$ exhibited a significant amount of healing of the crack when compared to the other samples and therefore, would have absorbed less water thanks to better crack healing.

There is a consistent trend in the reduction of water absorption in samples which had undergone biodeposition treatment both for uncracked and cracked samples, when compared to control samples. Microscopic and visual observations of the treated surfaces and healed cracks further confirmed this trend. Additional coatings were found to lead to a greater and more even coating of calcite crystals on the surface which can further improve the performance with respect to sorption.

\section{REFERENCES}

Borg, R. P., Cuenca, E., Gastaldo, E. M., and Ferrara, L. (2018b). Crack sealing capacity in chloride-rich environments of mortars containing different cement substitutes and crystalline admixtures. J. Sustain.

\section{CONCLUSION}

First and foremost, through this research, it was confirmed that MICP could be induced successfully on concrete using L. sphaericus and $\mathrm{CaCl}_{2}$ or L. sphaericus and $\left(\mathrm{Ca}\left(\mathrm{CH}_{3} \mathrm{COO}\right)_{2}\right)$ in the presence of urea. Furthermore, the characterization of the precipitates from the MICP process confirmed that the crystals precipitated on these samples were $\mathrm{CaCO}_{3}$ crystals. No difference in the amount of crystal precipitation was observed between samples treated with $L$. sphaericus and $\mathrm{CaCl}_{2}$ or $L$. sphaericus and $\left(\mathrm{Ca}\left(\mathrm{CH}_{3} \mathrm{COO}\right)_{2}\right)$. It was also noted that samples exposed to 2 rounds of treatment of $L$. sphaericus and a calcium source exhibited a greater and more even coating of calcite crystals on the surface. This proves that repeated cycles of treatment are effective in increasing the amount of $\mathrm{CaCO}_{3}$ deposition.

In terms of crack healing, since the bacteria was not protected against the high $\mathrm{pH}$ of the concrete, the amount of crack healing that could be observed visually was limited in certain areas. From digital microscopy, precipitates could be observed lining the side of the cracks and also bridging the crack at certain locations. Surface deposition of $\mathrm{CaCO}_{3}$ crystals was also observed. All the samples treated with L. sphaericus and a calcium source showed a degree of healing and/or plugging of its pores when tested. From UPV analysis, cracked samples which had undergone this treatment gave a higher pulse velocity than the control sample therefore indicating a degree of crack healing and pore plugging. Similarly, in terms of water absorption, samples which had undergone this treatment showed a reduction in the amount of water absorbed when compared to the control sample. This research confirmed the effective application of Lysinibacillus. sphaericus for surface treatment and crack healing of concrete.

\section{AUTHOR CONTRIBUTIONS}

The authors at the University of Malta were responsible for the design of the research and the implementation of experimental activity. All authors listed have made a substantial, direct and intellectual contribution to the work, and approved it for publication.

\section{ACKNOWLEDGMENTS}

The research was conducted at the University of Malta as part of the research programme in high performance self-healing cement based materials. The authors would like to acknowledge: ERDF (Malta) for the financing of the testing equipment through the project: Developing an Interdisciplinary Material Testing and Rapid Prototyping R\&D Facility (Ref. No. 012); Ing. J. Camilleri, University of Malta.

Cement Based Mater. 7, 141-159. doi: 10.1080/21650373.2017.14 11297

Borg, R. P., Hajek, P., and Ordonez, D. F. (2018a). Sustainable concrete: materials and structures. Mater. Sci. Eng. 442:011001. doi: 10.1088/1757-899X/442/1/011001fib 
Calcium carbonate (2016). Calcium Carbonate (Calcite). National Institute of Standards and Technology (NIST). Retrieved from: http://webbook.nist.gov/ cgi/cbook.cgi? ID=B6004659\&Mask=80

Chahal, N., and Siddique, R. (2011). Effect of ureolytic bacteria on concrete properties. Constr. Build. Mate. 25, 3791-3801. doi: 10.1016/j.conbuildmat.2011.04.010

Cuenca, E., Tejedor, A., and Ferrara, L. (2018). A methodology to assess crack-sealing effectiveness of crystalline admixtures under repeated cracking-healing cycles. Constr. Build. Mater. 179, 619-632. doi: 10.1016/j.conbuildmat.2018.05.261

De Belie, N., De Muynck, W., Van Tittelboom, K., and Verstraete, W. (2010b). Use of bacteria to repair cracks in concrete. Cement Concrete Res. 40, 157-166. doi: 10.1016/j.cemconres.2009.08.025

De Belie, N., De Muynck, W., and Verstraete, W. (2010a). Microbial carbonate precipitation in construction materials: a review. Ecol. Eng. 36, 118-136. doi: 10.1016/j.ecoleng.2009.02.006

De Belie, N., Gruyaert, E., Al-Tabbaa, A., Antonaci, P., Baera, C., Bajare, D., et al. (2018). A review of self-healing concrete for damage management of structures. Adv. Mater. Interf. 5:1800074. doi: 10.1002/admi.201800074

Dudi, A., Edwards, M., Parks, J., and Vikesland, P. (2010). Effects of bulk water chemistry on autogenous healing of concrete. J. Mater. Civil Eng. 22, 515-524. doi: 10.1061/(asce)mt.1943-5533.0000082

Escoffres, P., Desmettre, C., and Charron, J. P. (2018). Effect of a crystalline admixture on the self-healing capability of high-performance fiber reinforced concretes in service conditions. Construc. Build. Mater. 173, 763-774. doi: 10.1016/j.conbuildmat.2018.04.003

Farrugia, C., Borg, R. P., Buhagiar, J., and Ferrara, L. (2018). "Application of Lynsinibacillus sphaericus for concrete crack healing using different calcium sources," in SynerCrete 2018, Interdisciplinary Approaches for Cement-based
Materials and Structural Concrete, Final Conference of COST Action TU1404, eds M. Azenha, D. Schlicke, F Benboudjema, and A Jedrzejewska (Madeira: RILEM)

Ferrara, L., Krelani, V., and Carsana, M. (2014). A "fracture testing" based approach to assess crack healing of concrete with and without crystalline admixtures. Construc. Build. Mater. 68, 535-555. doi: 10.1016/j.conbuildmat.2014.07.008

Ferrara, L., Krelani, V., and Moretti, F. (2016). On the use of crystalline admixtures in cement based construction materials: from porosity reducers to promoters of self healing. Smart Mater. Struc. 25:8. doi: 10.1088/0964-1726/25/8/084002

Liberato, F., Van Mullem, T., Alonso, M. C., Antonaci, P., Borg, R. P., and Cuenca, E. (2018). Experimental characterization of the self-healing capacity of cement based materials and its effects on the material performance: a state of the art report by COST Action SARCOS WG2. Constr. Build. Mater. 167, 115-142. doi: 10.1016/j.conbuildmat.2018.01.143

Newman, J., and Seng Choo, B. (2003). Advanced Concrete Technology: Concrete Properties. Burlington, NY: Elsevier Ltd.

Conflict of Interest Statement: The authors declare that the research was conducted in the absence of any commercial or financial relationships that could be construed as a potential conflict of interest.

Copyright (C) 2019 Farrugia, Borg, Ferrara and Buhagiar. This is an open-access article distributed under the terms of the Creative Commons Attribution License (CC $B Y)$. The use, distribution or reproduction in other forums is permitted, provided the original author(s) and the copyright owner(s) are credited and that the original publication in this journal is cited, in accordance with accepted academic practice. No use, distribution or reproduction is permitted which does not comply with these terms. 